\title{
Proteome Analysis of Vernix Caseosa
}

\author{
MARIA TOLLIN, THERES JÄGERBRINK, ASGEIR HARALDSSON, BIRGITTA AGERBERTH, AND HANS JÖRNVALL \\ Department of Medical Biochemistry and Biophysics [M.T., T.J., B.A., H.J.], Karolinska Institutet, SE-17177 Stockholm, Sweden; \\ Children's Hospital Iceland, Landspitali - University Hospital and Faculty of Medicine [A.H.], University of Iceland, \\ 101 Reykjavik, Iceland
}

\begin{abstract}
Vernix caseosa (vernix) is a white creamy substance covering the skin of the fetus during the last trimester of pregnancy. The function of vernix has long been debated but no consensus has been reached. We here report a proteome analysis of vernix using two-dimensional gel electrophoresis, matrix-assisted laser desorption/ionization mass spectrometry and liquid chromatography coupled to tandem mass spectrometry. We have identified 41 proteins, of which 25 are novel to vernix. Notably, $39 \%$ of the identified vernix proteins are components of innate immunity, and $29 \%$ have direct antimicrobial properties. These results form a substantial contribution to the knowledge of vernix composition and demonstrate that antimicrobial protection of the fetus and the newborn child is a major and important function of vernix. (Pediatr Res 60: 430-434, 2006)
\end{abstract}

A white creamy substance designated Vernix caseosa (latin for "Cheese-like varnish") covers the skin of the fetus during the last trimester of pregnancy. The human is the only species known to produce this substance, and its function has been debated for decades. Many protective functions have been proposed, such as antimicrobial protection, heat insulation, moisturization and protection of the skin from macerating effects of the amniotic fluid. Other functions have also been suggested, such as hormonal effects, anti-inflammatory effects, nutritive functions, and facilitation of passage through the birth canal (1). Furthermore, vernix has been suggested to constitute a mechanical obstruction to bacterial passage (2). Recently, it was reported that vernix exhibits a skin cleansing function (3).

Early studies on whether vernix possesses direct antimicrobial activities yielded contradictory results $(1,2)$, most likely due to use of different antimicrobial assays. However, by preparation of a protein extract of vernix and identification of individual components we have proved that vernix contains potent antimicrobial polypeptides $(4,5)$. Members of the antimicrobial peptide families $\alpha$-defensins (Human Neutrophil Peptide, (HNP) 1-3) and cathelicidins (LL-37) have been identified in vernix, in addition to a number of antimicrobial proteins, i.e., psoriasin, secretory leukocyte protease inhibitor (SLPI) and calprotectin (calgranulin A and B) (4-6).

Received March 14, 2006; accepted May 30, 2006.

Correspondence: Hans Jörnvall, M.D., Ph.D., Department of Medical Biochemistry and Biophysics, Karolinska Institutet, SE-171 77 Stockholm, Sweden; E-mail: hans.jornvall@ki.se

Supported by grants from the Swedish Foundation for International Cooperation in Research and Higher Education (STINT), and The Swedish Research Council (06X11217, 13X-3532) and Karolinska Institutet.

DOI: $10.1203 / 01 . p d r .0000238253 .51224 . d 7$
In association with the discussion on the antimicrobial properties of vernix, there has been a debate on whether vernix should be left on the skin after birth $(7,8)$. Skin colonization of neonates was compared after leaving vernix on the skin and after bathing (removing vernix) the newborn. That study resulted in no difference in microbial colonization (8). However, the bathing reduced heat loss, and made the newborns calm, quiet and comfortable (8). The amount of vernix on the skin correlates with gestational age $(9,10)$. Preterm infants lacking vernix have a higher rate of nosocomial and community acquired infections (10).

The composition of vernix is water (81\%), lipids (9\%), and proteins (10\%) (11). Research on vernix has mainly focused on the lipid fraction (12-15), while the vernix proteins have long been neglected. However, in a recent study 18 vernix proteins were identified (5), but a comprehensive proteome analysis has to our knowledge not been performed of this material. We have therefore investigated the vernix proteome by 2-D (two-dimensional) gel electrophoresis, matrix-assisted laser desorption/ionization mass spectrometry (MALDI-MS) and liquid chromatography coupled to tandem mass spectrometry (LC-MS/MS), identifying many proteins novel to vernix. This now brings important insight into the role of vernix caseosa.

\section{MATERIALS AND METHODS}

Collection of vernix caseosa. Vernix caseosa was collected from the skin of newborns shortly after delivery, and before washing the neonates. The vernix samples were placed in sterile plastic containers and were immediately frozen and stored at $-20^{\circ} \mathrm{C}$ until analyzed. All newborns were without prenatal or perinatal complications, and without clinical signs of infection. The study was reported to the Data Protection Authority and the sample collection was approved by the parents.

Peptide/protein extraction. The vernix samples were extracted as recently described (5). Briefly, the samples were homogenized in $60 \%$ acetonitrile containing $1 \%$ (vol/vol) aqueous trifluoroacetic acid (TFA), and extracted during shaking overnight at $4^{\circ} \mathrm{C}$. After centrifugation of the extracts at 10,000 $\mathrm{g}$, the supernatants were lyophilised. The lyophilised material was dissolved in $0.1 \%$ (TFA) and loaded onto OASIS HLB cartridges (Waters). Bound proteins were eluted with $80 \%$ acetonitrile in $0.1 \%$ TFA and the eluates were lyophilized.

Abbreviations: LC-MS/MS, liquid chromatography tandem mass spectrometry; MALDI, matrix-assisted laser desorption/ionization; PLUNC palate lung nasal epithelial clone; RNase 7, ribonuclease 7; 2-D gel, two dimensional gel 
2-D gel electrophoresis. The protein content of samples was determined by the Bradford assay (16). Sample loads of $350-450 \mu \mathrm{g}$ protein were applied onto 17-cm Bio-Rad strips of pI 3-10 (Non Linear) via active in-gel rehydration. The sample (in $9 \mathrm{M}$ urea, $65 \mathrm{mM}$ DTT, 0.5\% Igepal CA 630, 1.5\% 3-[(3-Cholamidopropyl)dimethylammonio]-1-propanesulfonate (CHAPS), $5 \%$ ampholyte $3-10,35 \mathrm{mM}$ Tris, and complete proteinase inhibitor mix (Roche) was diluted with rehydration buffer (7 M urea, $2 \mathrm{M}$ thiourea, $4 \%$ wt/vol CHAPS, 0.5\% Igepal CA 630, 0.5\% ampholyte $3-10$ and $2.8 \mathrm{mg} / \mathrm{mL}$ DTT) to a final volume of $300 \mu \mathrm{L}$. The isoelectric focusing was carried out on a PROTEAN IEF (Bio-Rad) at $20^{\circ} \mathrm{C}$ as follows: $12 \mathrm{~h}$ at $50 \mathrm{~V}$ (active rehydration), $0-500 \mathrm{~V}$ for $1 \mathrm{~h}, 500 \mathrm{~V}$ for $1 \mathrm{~h}, 500-2000 \mathrm{~V}$ for $2 \mathrm{~h}, 2000-8000$ $\mathrm{V}$ for $1 \mathrm{~h}$ and finally $8000 \mathrm{~V}$ for $3.5 \mathrm{~h}$. All gradients were linear. After isoelectric focusing the strips were incubated for $15 \mathrm{~min}$ with $2 \%$ DTT in equilibration buffer (50 mM Tris- $\mathrm{HCl}, \mathrm{pH}$ 8.8, $6 \mathrm{M}$ urea, $30 \%$ glycerol, $2 \%$ SDS and a trace of bromphenol blue), followed by 15 min with $2.5 \%$ iodoacetamide in the same buffer. For the second dimension, proteins were separated in $15 \%$ polyacrylamide gels $(1.5 \times 260 \times 200 \mathrm{~mm})$ in an Ettan ${ }^{\mathrm{TM}}$ DALTsix system (Amersham). Electrophoresis was carried out at a constant current, $15 \mathrm{~mA} / \mathrm{gel}$ for $1 \mathrm{~h}$ and thereafter $40 \mathrm{~mA} / \mathrm{gel}$ until the bromophenol blue dye front was one $\mathrm{cm}$ from the gel bottom.

Coomassie staining. The gels were fixed over night with $2 \%$ phosphoric acid in $30 \%$ ethanol, washed for $3 \times 20 \mathrm{~min}$ in $2 \%$ phosphoric acid, and equilibrated for $30 \mathrm{~min}$ in equilibration buffer (2\% phosphoric acid/5\% aluminium sulphate/10\% ethanol). The gels were then stained for $2 \mathrm{~d}$ in $0.01 \%$ Coomassie brilliant blue G-250 in equilibration buffer, and destained in water.

In-gel digestion and protein fingerprinting. The gel spots were manually excised and digested with trypsin using a MassPREP robotic protein handling system (Micromass/Waters), employing a protocol described (17). Tryptic fragments were analyzed by MALDI-MS (Voyager DE-Pro, Applied Biosystems), using $\alpha$-cyano-4-hydroxycinnamic acid as matrix $(5 \mathrm{mg} / \mathrm{mL}$ in methanol:acetonitrile 1:1) and mixed 1:1 (vol/vol) with the sample. Database searches were carried out utilizing the ProteinProspector MS-Fit program (http://prospector.ucsf.edu/).

$\boldsymbol{L C}-\boldsymbol{M S} / \boldsymbol{M S}$. Tryptic digests were analyzed by liquid chromatography tandem mass spectrometry using Waters CapLC and Q-Tof Ultima API instruments. Before LC-separation, digests were desalted using an LCPackings Nano-Precolumn Cartridge (300 $\mu \mathrm{m}$ ID $\times 1 \mathrm{~mm}$; 5\% Acetonitril/ $0.1 \%$ formic acid; $20 \mu \mathrm{L} / \mathrm{min})$. A Waters Atlantis $\mathrm{C}_{18}$ column $(3 \mu \mathrm{m}, 100 \AA$, $75 \mu \mathrm{m} \mathrm{ID} \times 15 \mathrm{~cm}$ ) was used for LC separation and the peptides were eluted with a linear gradient of $14-50 \%$ acetonitrile in $0.1 \%$ formic acid for $20 \mathrm{~min}$ at $200 \mathrm{~nL} / \mathrm{min}$. Peptides were introduced into the mass spectrometer using a Pico Tip sprayer and data-dependent acquisition was used over a mass range of 300-2000 Da $(\mathrm{m} / \mathrm{z})$. Data analysis was performed using ProteinLynx Global SERVER 2.1 software (PLGS 2.1, Waters) and MassLynx peptide sequence software (version 4.0, Waters). Data sets were analyzed using the NCBI BLAST and Mascot search engines.

\section{RESULTS}

Vernix caseosa was collected from newborns directly after birth. The vernix proteins were extracted and separated by 2-D gel electrophoresis using 350-450 $\mu \mathrm{g}$ vernix protein per gel. Due to low amounts of protein from each neonate, and high inter-individual variation (5) (data not shown), material from several (five to nine) neonates were pooled for each preparative gel. Two gels were used for protein identification which had matching protein patterns, including areas of high background. Using a clean up system (2-D Clean Up kit, Amersham), did not reduce the background (data not shown). To better visualize the protein spots, the gels were combined using the 2-D analysis software PDQuest (Bio-Rad) to make a graphic picture (Fig. 1).

Most vernix proteins are of low molecular size (5), and are consequently located to the lower region of the 2-D gel (Fig. 1). However, the 2-D gel reveals that many large proteins are also present in the vernix extract. In total, we detected approximately 350 spots in each gel. Of these, 117 distinct protein spots were excised from the two gels and proteins were in-gel digested with trypsin. Using MALDI mass spec-

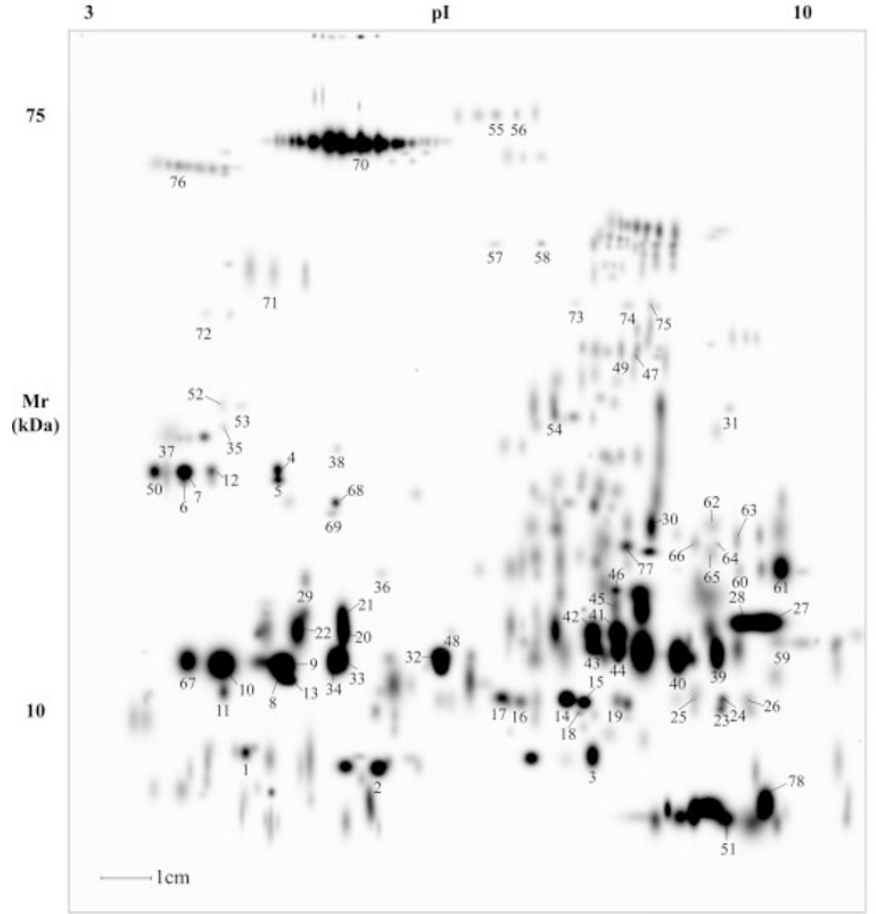

Figure 1. Graphic picture of proteins in Vernix caseosa separated on 2-D gel electrophoresis. Numbers indicate identified spots and are the same as those listed in (Table 1).

trometry and LC-MS/MS, 13 proteins were identified with MALDI, 16 with LC-MS/MS and 12 with a combination of the two methods (Table 1). Thereby, 41 proteins were identified in a total of 78 spots. Of these proteins, 16 (39\%) are involved in innate immunity and $12(29 \%)$ have been demonstrated to have direct antimicrobial activities.

\section{DISCUSSION}

In this study we have analyzed proteins in vernix caseosa with 2-D gel electrophoresis. The proteins identified are given in Table 1, and include 25 proteins novel to vernix. This is a substantial addition to the knowledge of the composition of vernix. Notably, several of the proteins are components of the innate immune system, compatible with a protective role of vernix against infection.

Vernix caseosa is a complex material. It has a high lipid content making the material difficult to work with. Consistently, a high background was seen in particular areas of the gels. It was probably derived from a high lipid content and an abundance of particular proteins including $\mathrm{Hb}$, profilaggrin and their fragments giving a trailing effect. This would be supported by the fact that we found these proteins over a large area of the gel (data not shown). To visualize the spots we therefore used the software PDQuest to produce a computerized image were the spots are clearly visible (Fig. 1).

Essentially all clearly visible spots were excised, and of the 117 protein spots analyzed, 41 proteins were identified in 78 spots. Many of the non-analyzed spots are concluded to be modified versions of the identified proteins. Typical sets of spots with multiple pIs but the same mass are noticed, representing differently modified proteins. Some were confirmed to 
Table 1. Proteins identified in vernix

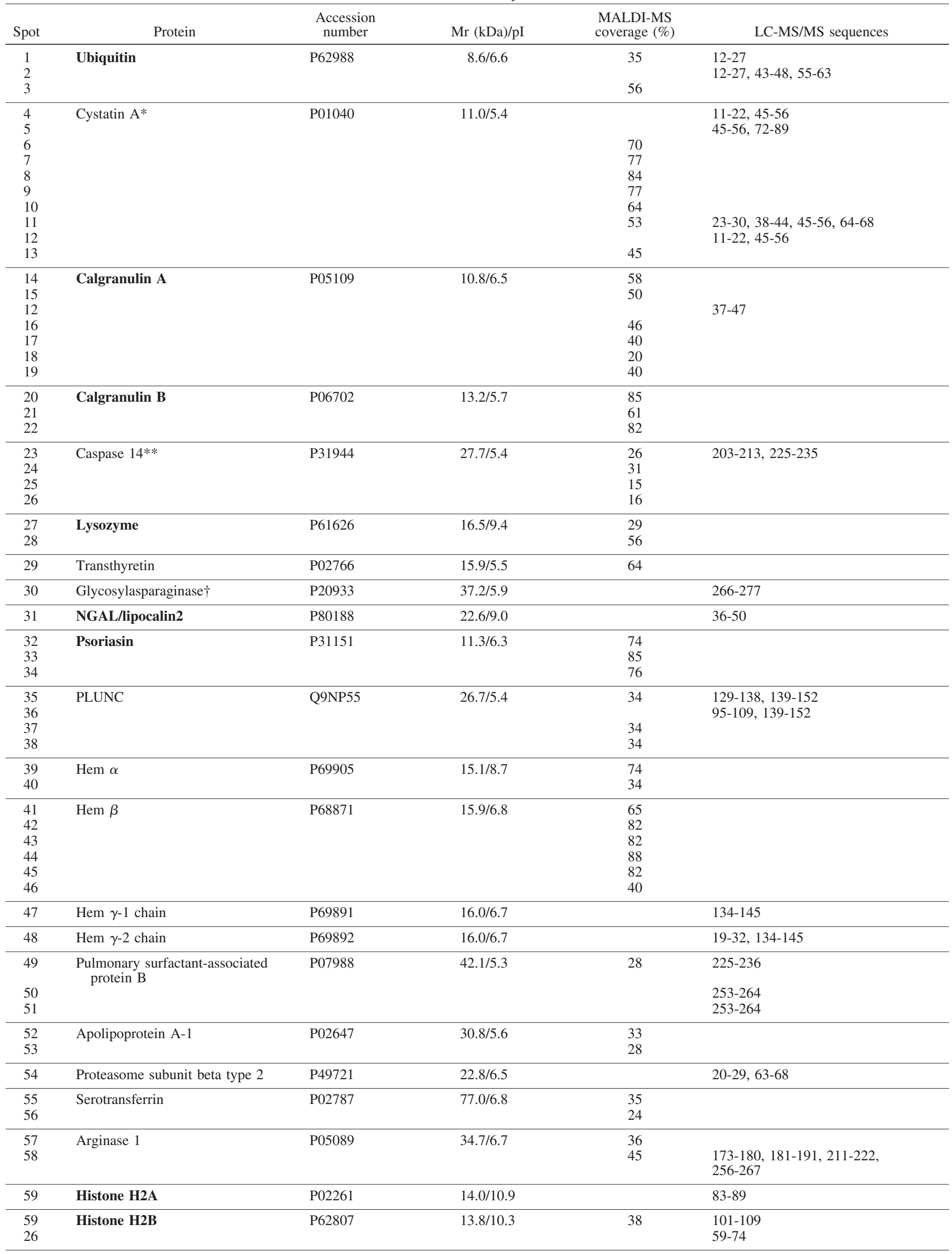


Table 1. Continued

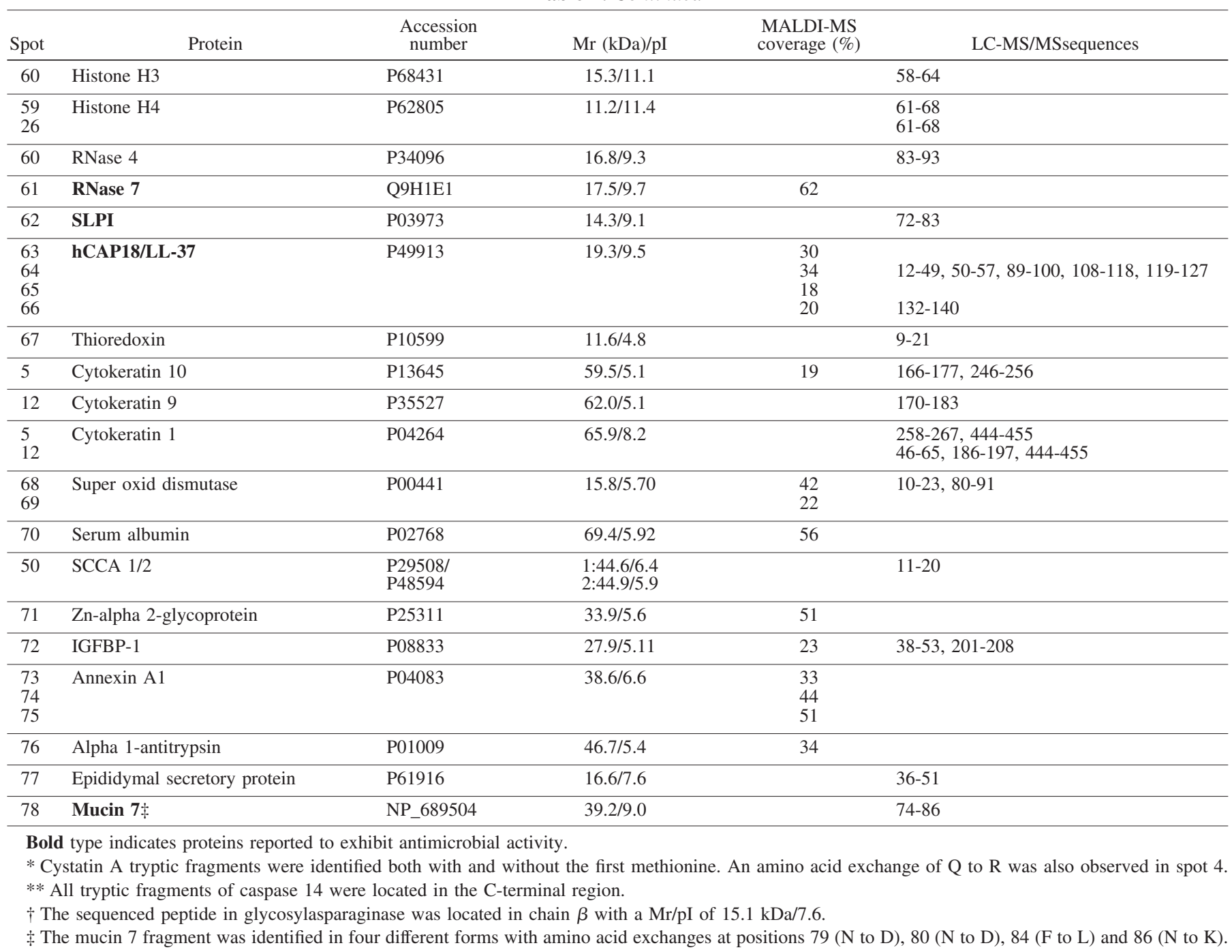

contain the same protein, e.g. serotransferrin (spots 55 and 56 in Fig. 1), and others are well known to produce such patterns, e.g. albumin (18). In addition, some proteins were localized to several spots with both different masses and pIs. Cystatin A, for example, was identified in ten spots with different localizations (spots 4-13 in Table 1 and Fig. 1), corresponding to post-translational modifications, complex formations or polymorphisms. For Cystatin A, we could show by MS/MS that at least one of the modifications was an amino acid exchange (Table 1, spot 4). Furthermore, in spot 78 we could identify a fragment of Mucin 7 in four different forms with multiple amino acid exchanges (Table 1 ). This likely reflects polymorphisms since the material originated from several neonates.

Origins of the vernix proteins are multiple. First, there is a close contact of vernix with the amniotic fluid, and therefore an exchange of proteins between vernix and the amniotic fluid is possible. Second, the amniotic fluid is also in contact with the fetal lungs and vernix can therefore contain lung proteins. Third, since the vernix material analyzed here was obtained from neonates delivered by vaginal deliveries there is a risk of blood contamination, consistent with the abundance of hemoglobins detected. Finally, many vernix proteins have dermal origins. Many of the identified proteins have been implicated in innate immunity.

One protein now detected in vernix is LL-37 (spots 63-66). We have previously demonstrated its presence, but only by highly sensitive immunologic methods (4). Here, we report that spots of LL-37 are detected by direct Coomassie staining after 2-D gel electrophoresis of vernix extract. This demonstrates the presence of high levels of LL-37 in vernix, more than previously considered. A contradictory result was reported recently, where LL-37 could not be detected in vernix extract (6), most likely depending on extraction in PBS instead of $60 \%$ acetonitrile with $1 \%$ TFA. Furthermore, fragments were here identified from both the cathelin and the processing regions, indicating that at least one of the identified LL-37 spots contains the unprocessed precursor and not only the cathelin region. Interestingly, apolipoprotein A-1 (spots 5253), the major LL-37-binding protein in blood (19) was also identified in vernix.

Palate lung nasal epithelial clone (PLUNC, also named LUNX and SPURT) is a protein expressed in the upper airways (20). This indicates that the PLUNC detected in vernix probably originates from the airways of the fetus. It 
was here found in multiple spots (spots 35-38), demonstrating the presence of several PLUNC isoforms in vernix. PLUNC isoform formation has previously been described in human nasal lavage fluid and modifications such as truncation, glycosylation, phosphorylation and de-amidation were proposed (21). PLUNC displays sequence homology and predicted structure similarity to the LPS binding proteins LBP and Bactericidal/Permeability Increasing protein (BPI) (22) and has been shown to be able to bind LPS (21). In rats, PLUNC is up-regulated in nasal respiratory epithelium upon olfactory neuronal injury, suggesting that PLUNC can provide protection to infection after injury (23). Because of these properties the family of PLUNC proteins has been proposed to have host defense functions $(22,24)$ and to work as sensors of Gramnegative bacteria in the oral cavity (24).

Neutrophil gelatinase-associated lipocalin (NGAL, also named human neutrophil lipocalin, uterocalin) is a bacteriostatic protein that interferes with the iron acquisition in bacteria through specific binding to bacterial chatecolate-type ferric siderophores (25). It is mainly expressed in neutrophils and tissues exposed to microbes such as trachea, uterus and colon (26). Hence, NGAL detected in vernix (spot 31) can originate from the maternal uterus and the neonatal respiratory tract or skin.

Ribonuclease 7 (RNase 7) was first isolated from stratum corneum of the skin and is an antimicrobial ribonuclease (27). RNase 7 is constitutively expressed in epithelial tissues including skin, respiratory tract, and uterus (27) but also in other tissues such as liver and kidney (28). It has also been shown to be induced in keratinocytes by certain bacteria (27). RNase 7 exhibits a broad spectrum of antimicrobial activity against many pathogens including vancomycin-resistant Enterococcus faecium (27). Our finding of RNase 7 in vernix (spot 61) suggests that it also is expressed in fetal skin thereby enhancing its role in innate immunity. Interestingly, another member of the ribonuclease A superfamily, RNase 4, was also identified in vernix (spot 60).

Annexins (spots 73-75) are a family of proteins that bind to phospholipids and carbohydrates in the presence of calcium ions. Annexin I has been shown to bind surface molecules of both Gram-positive and Gram-negative bacteria, i.e., lipoteichoic acids (29) and Lipid A (30). It has been shown to reduce neutrophil and monocyte infiltration in animal models (3133), and to suppress the attachment of Staphylococcus aureus to macrophages (29), activities that give Annexin I a role in inflammation.

In conclusion, our proteome analysis defines many proteins novel to vernix, with over one third related to innate immunity. This constitutes a substantial improvement to our knowledge of vernix and supports the conclusion that antimicrobial protection of the fetus is a major function of vernix.

Acknowledgments. We thank G. Alvelius and C. Palmberg for excellent assistance.

\section{REFERENCES}

1. Shulak B 1963 The antibacterial action of vernix caseosa. Harper Hosp Bull 21:111-117
2. Joglekar VM 1980 Barrier properties of vernix caseosa. Arch Dis Child 55:817-819

3. Moraille R, Pickens WL, Visscher MO, Hoath SB 2005 A novel role for vernix caseosa as a skin cleanser. Biol Neonate 87:8-14

4. Yoshio H, Tollin M, Gudmundsson GH, Lagercrantz H, Jornvall H, Marchini G, Agerberth B 2003 Antimicrobial polypeptides of human vernix caseosa and amniotic fluid: implications for newborn innate defense. Pediatr Res 53:211-216

5. Tollin M, Bergsson G, Kai-Larsen Y, Lengqvist J, Sjovall J, Griffiths W, Skuladottir GV, Haraldsson A, Jornvall H, Gudmundsson GH, Agerberth B 2005 Vernix caseosa as a multi-component defence system based on polypeptides, lipids and their interactions. Cell Mol Life Sci 62:2390-2399

6. Akinbi HT, Narendran V, Pass AK, Markart P, Hoath SB 2004 Host defense proteins in vernix caseosa and amniotic fluid. Am J Obstet Gynecol 191:2090-2096

7. Baker SM, Balo NN, Abdel Aziz FT 1995 Is vernix caseosa a protective material to the newborn? A biochemical approach. Indian J Pediatr 62:237-239

8. Henningsson A, Nystrom B, Tunnell R 1981 Bathing or washing babies after birth? Lancet 2:1401-1403

9. Behrman RE, Kliegman R, Jenson HB (eds) 2000 Nelson textbook of pediatrics. Philadelphia,W.B. Saunders Co., pp 1965-1974

10. Haubrich KA 2003 Role of Vernix caseosa in the neonate: potential application in the adult population. AACN Clin Issues 14:457-464

11. Hoeger PH, Schreiner V, Klaassen IA, Enzmann CC, Friedrichs K, Bleck O 2002 Epidermal barrier lipids in human vernix caseosa: corresponding ceramide pattern in vernix and fetal skin. Br J Dermatol 146:194-201

12. Haahti E, Nikkari T, Salmi AM, Laaksonen AL 1961 Fatty acids of vernix caseosa. Scand J Clin Lab Invest 13:70-73

13. Kaerkkaeinen J, Nikkari T, Ruponen S, Haahti E 1965 Lipids of Vernix Caseosa. J Invest Dermatol 44:333-338

14. Downing DT, Greene RS 1968 Double bond positions in the unsaturated fatty acids of vernix caseosa. J Invest Dermatol 50:380-386

15. Franzen B, Linder S, Okuzawa K, Kato H, Auer G 1993 Nonenzymatic extraction of cells from clinical tumor material for analysis of gene expression by twodimensional polyacrylamide gel electrophoresis. Electrophoresis 14:1045-1053

16. Bradford MM 1976 A rapid and sensitive method for the quantitation of microgram quantities of protein utilizing the principle of protein-dye binding. Anal Biochem $72: 248-254$

17. Hirschberg D, Tryggvason S, Gustafsson M, Bergman T, Swedenborg J, Hedin U, Jornvall H 2004 Identification of endothelial proteins by MALDI-MS using a compact disc microfluidic system. Protein J 23:263-271

18. Liberatori S, Bini L, De Felice C, Magi B, Marzocchi B, Raggiaschi R, Frutiger S, Sanchez JC, Wilkins MR, Hughes G, Hochstrasser DF, Bracci R, Pallini V 1997 A two-dimensional protein map of human amniotic fluid at 17 weeks' gestation. Electrophoresis 18:2816-2822

19. Sanchez JC, Converset V, Nolan A, Schmid G, Wang S, Heller M, Sennitt MV Hochstrasser DF, Cawthorne MA 2002 Effect of rosiglitazone on the differential expression of diabetes-associated proteins in pancreatic islets of $\mathrm{C} 57 \mathrm{Bl} / 6 \mathrm{lep} / \mathrm{lep}$ mice. Mol Cell Proteomics 1:509-516

20. Bingle CD, Bingle L 2000 Characterisation of the human plunc gene, a gene product with an upper airways and nasopharyngeal restricted expression pattern. Biochim Biophys Acta 1493:363-367

21. Ghafouri B, Kihlstrom E, Tagesson C, Lindahl M 2004 PLUNC in human nasal lavage fluid: multiple isoforms that bind to lipopolysaccharide. Biochim Biophys Acta 1699:57-63

22. Bingle CD, Craven CJ 2002 PLUNC: a novel family of candidate host defence proteins expressed in the upper airways and nasopharynx. Hum Mol Genet 11:937943

23. Sung YK, Moon C, Yoo JY, Pearse D, Pevsner J, Ronnett GV 2002 Plunc, a member of the secretory gland protein family, is up-regulated in nasal respiratory epithelium after olfactory bulbectomy. J Biol Chem 277:12762-12769

24. LeClair EE 2003 Four reasons to consider a novel class of innate immune molecules in the oral epithelium. J Dent Res 82:944-950

25. Goetz DH, Holmes MA, Borregaard N, Bluhm ME, Raymond KN, Strong RK 2002 The neutrophil lipocalin NGAL is a bacteriostatic agent that interferes with siderophore-mediated iron acquisition. Mol Cell 10:1033-1043

26. Cowland JB, Borregaard N 1997 Molecular characterization and pattern of tissue expression of the gene for neutrophil gelatinase-associated lipocalin from humans. Genomics 45:17-23

27. Harder J, Schroder JM 2002 RNase 7, a novel innate immune defense antimicrobial protein of healthy human skin. J Biol Chem 277:46779-46784

28. Gygi SP, Corthals GL, Zhang Y, Rochon Y, Aebersold R 2000 Evaluation of two-dimensional gel electrophoresis-based proteome analysis technology. Proc Natl Acad Sci USA 97:9390-9395

29. Gotoh M, Takamoto Y, Kurosaka K, Masuda J, Ida M, Satoh A, Takayama E, Kojima-Aikawa K, Kobayashi Y, Matsumoto I 2005 Annexins I and IV inhibit Staphylococcus aureus attachment to human macrophages. Immunol Lett 98:297302

30. Eberhard DA, Vandenberg SR 1998 Annexins I and II bind to lipid A: a possible role in the inhibition of endotoxins. Biochem J 330:67-72

31. Solito E, Romero IA, Marullo S, Russo-Marie F, Weksler BB 2000 Annexin 1 binds to U937 monocytic cells and inhibits their adhesion to microvascular endothelium: involvement of the alpha 4 beta 1 integrin. J Immunol 165:1573-1581

32. Perretti M, Ingegnoli F, Wheller SK, Blades MC, Solito E, Pitzalis C 2002 Annexin 1 modulates monocyte-endothelial cell interaction in vitro and cell migration in vivo in the human SCID mouse transplantation model. J Immunol 169:2085-2092

33. Allcock GH, Allegra M, Flower RJ, Perretti M 2001 Neutrophil accumulation induced by bacterial lipopolysaccharide: effects of dexamethasone and annexin 1 . Clin Exp Immunol 123:62-67 